Diabetologia (1994) 37: 1015-1024

Diabetologia

(c) Springer-Verlag 1994

\title{
Arterial hypertension and microalbuminuria in IDDM: The Italian Microalbuminuria Study
}

\author{
Report prepared by: R.Mangili ${ }^{1}$, G.Deferrari ${ }^{2}$, U.Di Mario ${ }^{3}$, O. Giampietro ${ }^{4}$, R. Navalesi ${ }^{4}$, R. Nosadini ${ }^{5}$, \\ G. Rigamonti ${ }^{6}$, R. Spezia ${ }^{6}$, G. Crepaldi ${ }^{5}$, for the Italian Microalbuminuria Study Group* \\ ${ }^{1}$ Department of Clinical Medicine, Scientific Institute San Raffaele, University of Milan, Italy \\ ${ }^{2}$ Department of Internal Medicine, University of Genoa, Italy \\ ${ }^{3}$ Department of Endocrinology and Metabolic Diseases, Policlinico Umberto I, University 'La Sapienza', Rome, Italy \\ ${ }^{4}$ Institute of Clinica Medica II, University of Pisa, Italy \\ ${ }^{5}$ Institute of Internal Medicine, Policlinico Universitario, University of Padua, Italy \\ ${ }^{6}$ Zeneca S. p. A., Basiglio, Milan, Italy
}

Summary Arterial hypertension and poor glycaemic control are central to the development of microalbuminuria in insulin-dependent diabetes mellitus (IDDM). Recent consensus has established sensitive criteria for their detection and treatment, although the proportion of patients who may benefit is unclear. Between 1988 and 1990, we measured urinary albumin to creatinine concentration ratio $(\mathrm{A} / \mathrm{C})$ in 3,636 adult out-patients with IDDM of more than 3 years duration, serum creatinine under $133 \mu \mathrm{mol} / 1$ and who were not undergoing antihypertensive treatment. $\mathrm{A} / \mathrm{C}$ indicating microalbuminuria $(\geq 2.38$ / $2.96 \mathrm{mg} / \mathrm{mmol}$, male/female) was found in 620 of 3,451 patients without proteinuria, and associated with hypertension (blood pressure $\geq 140$ and/or $90 \mathrm{~mm} \mathrm{Hg} ; p=0.0016$; rate: $39.6 \%$ ), independent of diabetes duration $(p=0.0082)$ and male gender ( $p=0.0350$; relative risk $=1.16 ; 95 \%$ confidence interval: 1.01-1.32). Hypertension was less common among those with normal $\mathrm{A} / \mathrm{C}(27.5 \%, p<0.0001)$ but was positively related with diabetes duration. Of the 1,015 patients with $\mathrm{A} / \mathrm{C} \geq 2.0 \mathrm{mg} / \mathrm{mmol} 529$ were reexamined. Glycated haemoglobin levels exceeded 3 SD above the mean of normal in $84.3 \%$ of the 198 microalbuminuric patients (AER $=20$ $200 \mu \mathrm{g} / \mathrm{min})$, but were comparably poor $(79.2 \%)$ in normoalbuminuria. Duration of diabetes was inversely related to glycated haemoglobin only in microalbuminuria $(0.05<p<0.1)$. Intervention to lower blood pressure remains mainly restricted to those patients with long-term diabetes and slower development of kidney disease. Near-normalisation of glycaemia remains the priority for the majority of patients with microalbuminuria. [Diabetologia (1994) 37: 1015-1024]

Key words Insulin-dependent diabetes mellitus, arterial hypertension, borderline hypertension, microalbuminuria, diabetic nephropathy.
The long-term prognosis of IDDM is linked to the onset of kidney disease. Clinical proteinuria develops in $30-40 \%$ of these patients $[1,2]$, eventually leading to

* See a full list of Members after the acknowledgements

Received: 11 November 1993

and in final revised form: 15 April 1994

Corresponding author: Dr. R.Mangili, Cattedra di Clinica Medica Generale e Terapia Medica VII, Università degli Studi di Milano, Istituto Scientifico San Raffaele, Via Olgettina, 60, I-20132 Milano, Italy

Abbreviations: UAlb, Urinary albumin concentration; A/C, urinary albumin to creatinine concentration ratio; AER, urinary albumin excretion rate; C.I., confidence interval; $d f$, degrees of freedom. end-stage renal failure and renal replacement therapy. IDDM is characterised by a high rate of cardiovascular morbidity and mortality, which is predominantly explained by the subset of patients with renal disease $[3,4]$. The biological mechanisms underlying the association of proteinuria with cardiovascular events are still unclear, but arterial hypertension is an established risk factor for cardiorenal mortality among long-term IDDM patients [5], and both the course of kidney disease and mortality can benefit from near-normalisation of blood pressure following pharmacological intervention at the stage of clinical nephropathy [6-8].

Although blood pressure levels are often within the World Health Organisation criteria for arterial 


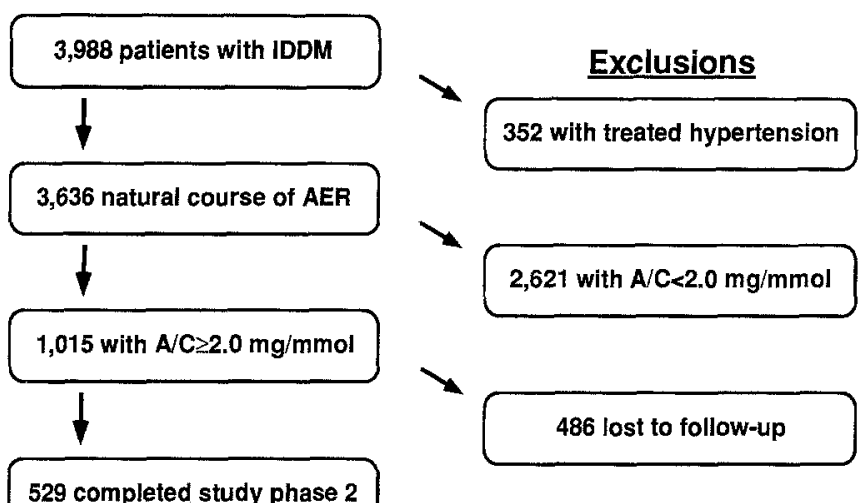

Fig. 1. Diagram of the selection of patients through both study phases

hypertension among diabetic patients without proteinuria [9-12], sub-clinical increases in blood pressure can predict the onset of clinical proteinuria [13, 14 , perhaps in parallel with microalbuminuria [1519], and their pharmacologic correction is known to slow the progression of microalbuminuria $[20,21]$. The recent extension of detection and treatment criteria for arterial hypertension to include diabetic patients with borderline hypertension [22] may be particularly relevant to those with microalbuminuria [23].

The proportion of either risk factor is unclear in Mediterranean countries, and studies of the prevalence of hypertension and microalbuminuria in large groups of patients with IDDM have never considered borderline hypertension [9-11]. Metabolic abnormalities are another established factor in the progression of microalbuminuria [14, 24-26], and sensitive criteria for the detection of poor glycaemic control are likewise recommended in the secondary prevention of diabetic nephropathy [23], although the proportion of patients who may benefit from nearnormalising glycaemia in ordinary clinical practice is likewise unclear. We therefore decided to study arterial hypertension and microalbuminuria in IDDM, and examined the cross-sectional relationship of microalbuminuria with blood pressure and glycaemic control.

\section{Patients and methods}

Study design. Assuming that there is a lower incidence of microalbuminuria in a Mediterranean country than in England, as found in a preliminary report which suggested a rate of $5.7 \%$ [27], we studied a group of more than 3,000 patients with IDDM which was considered adequate to identify at least 100 patients with microalbuminuria. The study was designed as a cross-sectional multi-centre screening in two phases, with a standardised collection of clinical and chemical data from independent observers and laboratories. There were no geographic criteria in the choice of the distribution of centres [28]. Tertiary referral centres co-ordinated the ac- tivity of the secondary referral centres located in the same region, equally selecting patients on a secondary referral basis.

Selection criteria. Patients were selected at phase 1 to attend one of the participating diabetes outpatient clinics for at least 6 months following the first visit. Informed consent was verbally obtained from all patients, who had diabetes for more than 3 years, between the ages of 16-65 years, with known serum creatinine less than $133 \mu \mathrm{mol} / 1(1.5 \mathrm{mg} / \mathrm{dl})$, and absence of persistent urinary sediment abnormalities and/or non-diabetic kidney disease. At this stage, basic demographics, antihypertensive treatment, serum creatinine concentration, and blood pressure were measured and recorded. A single non-timed urine sample was obtained from each patient to measure $A / C$, and indicate the presence of microalbuminuria. Local observers had no knowledge of current urinary albumin excretion, which had not been routinely tested at most of the secondary referral centres at the time of the study (1988-1990).

Of the 3,988 patients meeting the above criteria, 352 were being treated for hypertension (Fig. 1) and were therefore excluded, because of the confusing effect of antihypertensive treatment upon AER and on the natural course of diabetic kidney disease. Of the remaining 3,636 patients, only those with $\mathrm{A} / \mathrm{C}$ over $2.0 \mathrm{mg} / \mathrm{mmol}$ were subsequently considered for phase 2 evaluation, although only 529 patients $(52.1 \%)$ submitted three consecutive timed overnight urine collections for the measurement of AER. Comparisons of their clinical features at phase 1 with those of the patients who failed to complete the study suggested similarities in duration of diabetes $(16.8 \pm 8.8$ vs $16.9 \pm 8.1$ years, $p=\mathrm{NS}), \mathrm{A} / \mathrm{C}(6.6 \times / \div 2.8$ vs $7.2 \times / \div 3.3 \mathrm{mg} / \mathrm{mmol}$, geometric mean $x / \div$ tolerance factor, $p=\mathrm{NS}$ ) and proportion of male patients (52.4 vs $51.8 \%$, $p=$ NS), but patients who completed the study were younger $(39.1 \pm 13.2$ vs $40.7 \pm 12.7$ years, $p=0.035)$ and had lower blood pressures (systolic: $130.2 \pm 17.2$ vs $132.5 \pm 18.1 \mathrm{~mm} \mathrm{Hg}$, $0.05<p<0.1$; diastolic: $79.7 \pm 8.4$ vs $81.3 \pm 9.2 \mathrm{~mm} \mathrm{Hg}, p=$ $0.0023)$.

On the second visit, body weight and height were measured and recorded along with blood pressure and total daily insulin. Blood was taken for measurement of glycated haemoglobin, blood glucose and serum creatinine, while the patients were in the fasting state.

Clinical and laboratory methods. Single blood pressure recordings (Korotkoff phases I/V) to the nearest $5 \mathrm{~mm} \mathrm{Hg}$ were taken on each visit after 5-min rest with an ordinary mercury sphygmomanometer, with appropriately sized cuffs. Body weight was obtained in light indoor clothing, and height was measured with no shoes. Body mass index was calculated and expressed in $\mathrm{kg} / \mathrm{m}^{2}$. Single void, non-timed urine samples were collected with no preservative added. Timed overnight urine samples were collected in bottles with preservative (Thimerosal, Sigma Chemical Co., St. Louis, MO, USA; $500 \mu \mathrm{l}$ of a $1 \mathrm{~g} / \mathrm{l}$ solution per bottle; and $\mathrm{NaOH}, 500 \mu \mathrm{l}$ of a $4 \mathrm{~mol} / 1$ solution per bottle). All urine samples were aliquoted and stored at $-20^{\circ} \mathrm{C}$ or less until analysis. The measurements of UAlb (RIA; either Pharmacia, Uppsala, Sweden; or SCLAVO, Cinisello Balsamo, Italy) and urinary creatinine (Jaffè reaction) [29] were centralised by region, with a total of nine laboratories. The inter-laboratory coefficient of variation in UAlb, as evaluated by an external quality control programme, was $40 \%$ around $3.4 \mathrm{mg} / \mathrm{l}$, but less than $15 \%$ at concentrations in the microalbuminuric range was acceptable [30]. The variability in the measurement of urinary creatinine concentration was comparable with the preliminary stage of the study [28]. Serum creatinine and blood glucose (routine enzymatic-colorimetric 
Table 1. Rates of macroalbuminuria (UAlb $\geq 150 \mathrm{mg} / \mathrm{l}$ ) and microalbuminuria (UAlb $<150 \mathrm{mg} / \mathrm{l}$, but $\mathrm{A} / \mathrm{C}$ higher than the indicated gender-specific levels) by gender and duration of diabetes among 3,636 patients without treated hypertension fulfilling phase 1 entry criteria

\begin{tabular}{|c|c|c|c|c|c|c|c|c|c|c|}
\hline \multirow{2}{*}{$\begin{array}{l}\text { Duration } \\
\text { of IDDM } \\
\text { (years) }\end{array}$} & \multicolumn{5}{|l|}{ Men } & \multicolumn{5}{|c|}{ Women } \\
\hline & $n$ & \multicolumn{2}{|c|}{$\begin{array}{l}\mathrm{UAlb}<150 \mathrm{mg} / \mathrm{l} \\
\mathrm{A} / \mathrm{C} \geq 2.38 \mathrm{mg} / \mathrm{mmol}\end{array}$} & \multicolumn{2}{|c|}{$\mathrm{UAlb} \geq 150 \mathrm{mg} / 1$} & $n$ & \multicolumn{2}{|c|}{$\begin{array}{l}\mathrm{UAlb}<150 \mathrm{mg} / \mathrm{l} \\
\mathrm{A} / \mathrm{C} \geq 2.96 \mathrm{mg} / \mathrm{mmol}\end{array}$} & \multicolumn{2}{|c|}{$\mathrm{UAlb} \geq 150 \mathrm{mg} / \mathrm{l}$} \\
\hline $04-05$ & 254 & 11.8 & $8.2-16.6$ & 1.6 & $0.5-4.2$ & 170 & 11.2 & $7.0-17.1$ & 3.5 & $1.4-7.9$ \\
\hline $06-10$ & 479 & 13.6 & $10.7-17.0$ & 3.3 & $2.0-5.4$ & 374 & 12.6 & $9.4-16.5$ & 2.1 & $1.0-4.3$ \\
\hline $11-15$ & 445 & 19.3 & $15.8-23.4$ & 6.5 & $4.5-9.3$ & 354 & 17.5 & $13.8-21.9$ & 2.8 & $1.4-5.3$ \\
\hline $26-30$ & 121 & 24.8 & $17.6-33.6$ & 8.3 & $4.2-15.0$ & 141 & 22.7 & $16.3-30.7$ & 2.8 & $0.9-7.5$ \\
\hline $31+$ & 103 & 28.2 & $19.9-38.0$ & 9.7 & $5.0-17.5$ & 94 & 7.4 & $3.3-15.2$ & 8.5 & $4.0-16.6$ \\
\hline All strata & 1971 & 18.1 & $16.4-19.9$ & 5.9 & $4.9-7.1$ & 1665 & 15.8 & $14.1-17.7$ & 4.1 & $3.2-5.2$ \\
\hline
\end{tabular}

methods) were likewise centralised at the same laboratories. Glycated haemoglobin was measured locally, and depended on $\mathrm{HbA}_{\mathrm{I}}$ or $\mathrm{HbA}_{\mathrm{Ic}}$ determinations; data were then individually readjusted to the local mean and SD of normal, and expressed in number of SD above the mean of normal [23].

Diagnostic criteria. The diagnosis of IDDM was established by the presence of insulin-treated, ketosis-prone diabetes with onset before the age of 40 years. Poor glycaemic control was defined as glycated haemoglobin levels more than $3 \mathrm{SD}$ above the mean of normal [23]. The diagnosis of arterial hypertension was consistent with WHO criteria, but normal blood pressure was restricted to the patients with systolic/diastolic recordings less than 140 and $90 \mathrm{~mm} \mathrm{Hg}$, respectively, to comply with recent consensus [23]. The finding of AER in the range of $20-200 \mu \mathrm{g} / \mathrm{min}$ in at least two out of three sterile (nitriteand leucocyte-dipstick negative) collections established the presence of microalbuminuria.

For the purpose of statistical analysis, albuminuria measurements obtained during study phase 1 were categorised by the use of UAlb and A/C levels as previously stated [28]. In line with the traditional use of concentration (dipstick-reagent) tests for the diagnosis of clinical proteinuria, UAlb over $150 \mathrm{mg} / \mathrm{l}$ was used to suggest the presence of AER over $200 \mu \mathrm{g} / \mathrm{min}$. Among the patients with lower UAlb, A/ $\mathrm{C} \geq 2.38 / 2.96 \mathrm{mg} / \mathrm{mmol}$ (male/female) was assumed to detect AER higher than $20 \mu \mathrm{g} / \mathrm{min}$ with $77 \%$ sensitivity and $78 \%$ positive predictive value. As more than $20 \%$ of the patients with microalbuminuria have $\mathrm{A} / \mathrm{C}$ less than the above levels, a borderline range was considered, and $\mathrm{A} / \mathrm{C}$ under $1.20 /$ $1.52 \mathrm{mg} / \mathrm{mmol}$ (male/female) was taken to suggest AER under $20 \mu \mathrm{g} / \mathrm{min}$ with a predictive value over $99 \%$.

\section{Statistical analysis}

Data were analysed by the use of commercial software packages (SAS and JMP; SAS Institute Inc., Cary, NC, USA), and are presented as arithmetic mean with SD or rates with $95 \%$ C.I. Variables deviating from the normal distribution (significant Kolmogorov-Smirnov-Lilliefors or Wilks-Shapiro test, according to a sample size of larger or smaller than 2000) were conservatively rank-averaged before analysis, as appropriate. Differences between groups were addressed by one-way analysis of variance, allowing for unequal variance according to Welch, and significance was adjusted for multiple comparisons by the Tuckey-Kramer test. Simple relationships bet- ween categorical effects were addressed by contingency table analysis. Multiple regression, analysis of covariance and logistic models were addressed by the general linear models procedure after rank-transformation of all continuously distributed variables. Reports include the number of $d f$ due to model and effect components, which are directly relevant to chi squarebased analyses. The $d f$ due to error, as relevant to $F$ Ratio statistics, can be obtained by $[n-(1+d f)]$, where $n$ is the total number of observations. As statistical associations were similar before and after rank-transformation the usual parametric analyses were chosen for model presentation, with beta-coefficients indicating the change in the dependent variable per unit increase of the independent variable. The null hypothesis was rejected for two-tailed $p$ levels below $5 \%$.

\section{Results}

Study phase 1. Raised UAlb and A/C levels, respectively, suggesting the presence of AER in the macroand microalbuminuric range, were found for all diabetes durations, both among male and female patients (Table 1). Male gender and duration of diabetes were positively associated with greater probability of $\mathrm{UAlb} \geq 150 \mathrm{mg} / \mathrm{l}\left(n=3636\right.$; whole model $R^{2}=0.028$, $p<0.0001$; gender: $p=0.0051$; duration of diabetes: $p<0.0001$ ) and $\mathrm{A} / \mathrm{C}$ in the range of microalbuminuria among those with UAlb $<150 \mathrm{mg} / \mathrm{l}(n=3451$; whole model $R^{2}=0.014, p<0.0001$; gender: $p=0.0098$; duration of diabetes: $p<0.0001$ ), although the raw relative risk for men was just above 1 both for the presence of UAlb $>150 \mathrm{mg} / 1(1.48 ; 95 \%$ C.I. $=1.09-2.00)$ and for the presence of $\mathrm{A} / \mathrm{C}$ in the microalbuminuric range $(1.16 ; 95 \%$ C. $I .=1.01-1.32)$. Details of the clinical features of patients at phase 1 were also consistent with parallel associations of raised urinary albumin with older age and higher blood pressures, with arterial and borderline hypertension together characterising up to $40 \%$ of the patients with $\mathrm{A} / \mathrm{C}$ in the microalbuminuric range (Table 2 ).

Among the patients with UAlb less than $150 \mathrm{mg} / \mathrm{l}$, having $\mathrm{A} / \mathrm{C}$ in the microalbuminuric range remained independently related to hypertension $(p=0.0016)$, 
Table 2. Details of 3,636 IDDM patients without treated hypertension fulfilling phase 1 selection criteria

\begin{tabular}{|c|c|c|c|c|c|}
\hline \multirow{4}{*}{$\begin{array}{l}\text { (Male) } \\
\text { (Female) }\end{array}$} & \multicolumn{5}{|c|}{ Urinary albumin concentration } \\
\hline & \multicolumn{3}{|l|}{$<150 \mathrm{mg} / 1$} & \multicolumn{2}{|l|}{$\geq 150 \mathrm{mg} / \mathrm{l}$} \\
\hline & \multicolumn{3}{|c|}{ Urinary A/C ratio (mg/mmol) } & & \\
\hline & $<1.52$ & $1.52-2.95$ & $\geq 2.96$ & & \\
\hline Group & A & $B$ & $\mathrm{C}$ & $\mathrm{D}$ & $p$-value \\
\hline Duration of diabetes (years) & $14.6 \pm 8.4$ & $14.9 \pm 8.1$ & $16.8 \pm 8.3^{\mathrm{a}}$ & $18.4 \pm 8.8^{\mathrm{a}}$ & $<0.0001$ \\
\hline Systolic blood pressure $(\mathrm{mm} \mathrm{Hg})$ & $126.1 \pm 14.9$ & $129.1 \pm 16.6^{b}$ & $130.7 \pm 16.9^{\mathrm{b}}$ & $136.1 \pm 18.8^{\mathrm{c}}$ & $<0.0001$ \\
\hline Diastolic blood pressure ( $\mathrm{mm} \mathrm{Hg}$ ) & $78.4 \pm 8.3$ & $79.5 \pm 8.4^{\mathrm{b}}$ & $80.3 \pm 8.7^{b}$ & $82.5 \pm 8.7^{c}$ & $<0.0001$ \\
\hline Known serum creatinine $(\mu \mathrm{mol} / \mathrm{l})$ & $77.6 \pm 15.8$ & $76.3 \pm 16.0$ & $77.4 \pm 17.6$ & $85.1 \pm 20.2^{c}$ & $<0.0001$ \\
\hline Arterial hypertension (\%) & $5.3(4.5-6.4)$ & $9.7(7.5-12.6)$ & $10.6(8.4-13.4)$ & $18.9(13.7-25.5)$ & $<0.0001$ \\
\hline Borderline hypertension (\%) & $22.2(20.5-24.0)$ & $25.5(22.0-29.3)$ & $29.0(25.5-32.8)$ & $35.1(28.4-42.5)$ & $<0.0001$ \\
\hline
\end{tabular}

Data are arithmetic mean \pm SD or rates with $95 \%$ confidence limits in parentheses.

${ }^{a} p<0.05$ vs groups $\mathrm{A}$ and $\mathrm{B},{ }^{b} p<0.05$ vs group $\mathrm{A}$ and $\mathrm{D}$, and ${ }^{c} p<0.05$ vs all other groups, allowing for multiple comparisons

Table 3. Rates of hypertension by duration of diabetes and urinary albumin to creatinine ratio among 3,451 IDDM patients with $\mathrm{UAlb}<150 \mathrm{mg} / \mathrm{l}$ without treated hypertension fulfilling phase 1 entry criteria

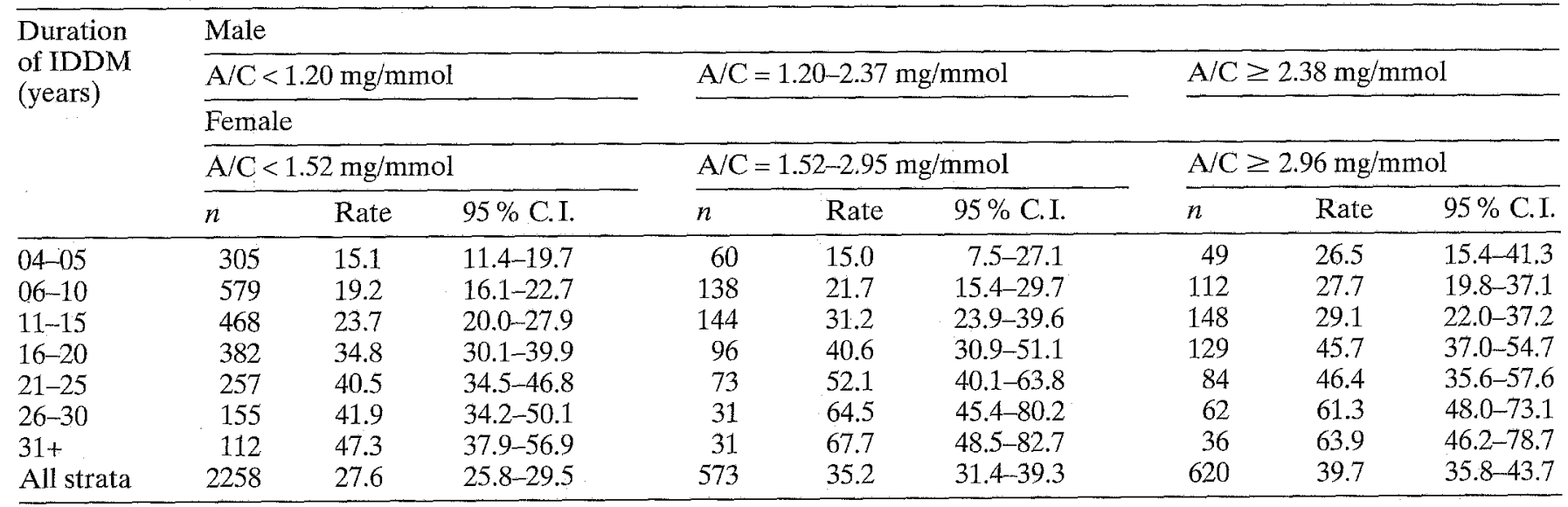

male gender $(p=0.0350)$, and duration of diabetes $(p=0.0082)$ weighing for the effects of age $(p=\mathrm{NS})$ and laboratory of measurement $(p<0.0001)$ in a multiple logistic regression model $(n=3451$; whole model $\left.R^{2}=0.026, p<0.0001\right)$. Comparable rates of hypertension were present, however, among those with borderline A/C (Table 2). Table 3 shows unadjusted rates of hypertension by duration of diabetes and $\mathrm{A} /$ C levels.

Linear models reciprocally addressing the concomitants of systolic and diastolic blood pressure reconfirmed a positive and significant effect of $\mathrm{A} / \mathrm{C}$ among the patients with UAlb $<150 \mathrm{mg} / \mathrm{l}$ independent of the parallel associations of blood pressures with age and male gender (Table 4). There was also an independent relationship between systolic blood pressure and diabetes duration.

Study phase 2. Of the 529 patients who completed the study, 47 had macroalbuminuria and 198 had microalbuminuria, yielding a proportionally recalculated rate of microalbuminuria of $10.7 \%$ out of the nonmacroalbuminuric patients, which did not account for the $89 \%$ sensitivity of the screening technique [28].

Comparisons of their clinical features with the 284 patients who turned normoalbuminuric reconfirmed the above described associations of raised AER with older age, male gender, longer duration of diabetes and higher blood pressure (Table 5). Rates of arterial and borderline hypertension approximated phase 1 findings in the corresponding subsets. In addition, AER was paralleled by small but significant differences in body mass index and serum creatinine, whereas differences in daily insulin dose, blood glucose and glycated haemoglobin levels were not significant. Likewise, poor glycaemic control characterised a majority of the patients in both groups.

Simple regression analyses indicated that among the patients with microalbuminuria there were borderline inverse relationships of diabetes duration 
Table 4. Study phase 1. Linear models examining the influence of the $\mathrm{A} / \mathrm{C}$ ratio on systolic and diastolic blood pressure among 3,451 IDDM patients with urinary albumin concentration less than $150 \mathrm{mg} / \mathrm{l}$ and without treated hypertension

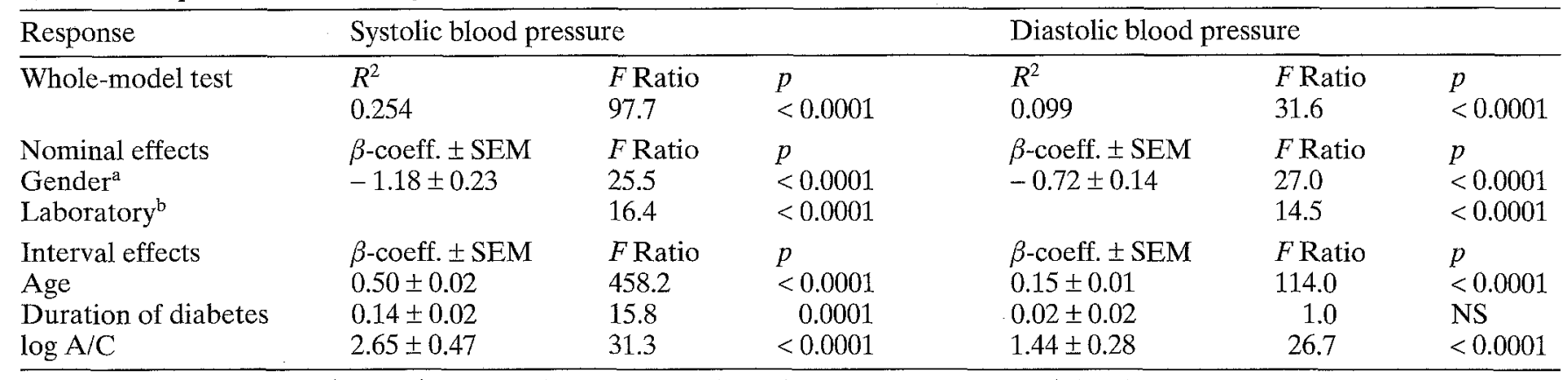

a The least square means $( \pm$ SEM) were higher among male patients both for systolic $(128.31 \pm 0.34 \mathrm{vs} 125.95 \pm 0.36 \mathrm{~mm} \mathrm{Hg})$ and for diastolic blood pressure $(79.63 \pm 0.20$ vs $78.20 \pm 0.22)$. ${ }^{\text {b }}$ Parameter estimates $(n=8)$ were omitted because not relevant to pathophysiology

Table 5. Clinical characteristics of 529 IDDM patients who completed phase 2 evaluation

\begin{tabular}{|c|c|c|c|c|}
\hline & Normoalbuminuria & Microalbuminuria & Macroalbuminuria & $p$-value \\
\hline Number and sex (male/female) & $112 / 172$ & $129 / 69$ & $36 / 11$ & $<0.0001$ \\
\hline Age (years) & $36.4 \pm 13.1^{\mathrm{a}}$ & $41.4 \pm 13.2$ & $45.3 \pm 10.1$ & $<0.0001$ \\
\hline Duration of diabetes (years) & $15.5 \pm 8.6^{\mathrm{a}}$ & $18.0 \pm 8.9$ & $19.7 \pm 8.3$ & 0.0005 \\
\hline Body mass index $\left(\mathrm{kg} / \mathrm{m}^{2}\right)$ & $23.7 \pm 3.2$ & $24.4 \pm 3.2$ & $26.0 \pm 4.7^{\mathrm{a}}$ & 0.0014 \\
\hline Insulin dose $(\mathrm{IU} / 24 \mathrm{~h})$ & $41.6 \pm 14.0$ & $43.9 \pm 16.8$ & $45.5 \pm 18.6$ & $\mathrm{NS}$ \\
\hline Blood glucose (mmol/l) & $10.9 \pm 4.3$ & $11.4 \pm 4.7$ & $12.1 \pm 4.1$ & NS \\
\hline Systolic blood pressure (mm Hg) & $126.5 \pm 15.6^{\mathrm{a}}$ & $134.4 \pm 16.1$ & $139.1 \pm 18.0$ & $<0.0001$ \\
\hline Diastolic blood pressure ( $\mathrm{mm} \mathrm{Hg}$ ) & $79.6 \pm 7.8^{\mathrm{a}}$ & $82.5 \pm 8.3$ & $84.0 \pm 7.6$ & $<0.0001$ \\
\hline Arterial hypertension (\%) & $6.7(4.2-10.4)$ & $12.6(8.5-18.3)$ & $23.4(12.8-38.4)$ & 0.001 \\
\hline Borderline hypertension (\%) & $19.7(15.3-24.9)$ & $35.9(29.3-43.0)$ & $34.0(21.3-49.4)$ & 0.0001 \\
\hline
\end{tabular}

Overall statistical significance by analysis of variance or contingency table analysis. ${ }^{\mathrm{a}} p<0.05$ vs both of the other groups. ${ }^{\mathrm{b}}$ Expressed in number of SD above the mean of normal. ${ }^{c}$ Glycated haemoglobin levels higher than 3 SD above the mean of normal

with insulin dose $(\beta$-coefficient \pm SEM: $-0.26 \pm 0.13$, $0.05<p<0.1)$ and glycated haemoglobin levels $(-0.050 \pm 0.027,0.05<p<0.1)$. Among those with normoalbuminuria, there was a negative association with insulin dose $(-0.25 \pm 0.10, p=0.0102)$, though not with glycated haemoglobin levels $(-0.02 \pm 0.02$; $p=$ NS). Duration of diabetes was positively correlated with age, blood pressure and serum creatinine in both of the non-proteinuric groups.

Multiple regression analyses suggested that blood pressure was independently associated with diabetes duration only among those patients with microalbuminuria, whereas age and body mass index were the main concomitants of systolic and diastolic blood pressure in the subset of normoalbuminuric patients, also after allowing more variables of putative relevance to blood pressure in the statistical models (Table 6).

\section{Discussion}

This study reports the rates of microalbuminuria in a large group of IDDM outpatients without clinical proteinuria, addressing for the first time the proportion of these patients who may be candidates for antihypertensive treatment and near-normalisation of glycaemic control $[22,23]$. Furthermore, analyses of the concomitants of raised urinary albumin agree with known positive and independent associations with male gender $[1,9,11,12,31,32]$, duration of diabetes $[9,11]$ and blood pressure [9-12,33].

In contrast with an initial screening estimate of $17.9 \%$ from $\mathrm{A} / \mathrm{C}$ of single random urine samples, the recalculated rate of microalbuminuria was only $10.7 \%$ after multiple measurements of AER in overnight collections. However, both the incomplete sensitivity of the operative $\mathrm{A} / \mathrm{C}$ cut-off level [28] and the clinical features of the patients who were re-examined were consistent with a negative selection bias during the second phase of the study. Also, daytime increases in albumin excretion [34], reflecting the acute effects of dietary protein intake [35] and 


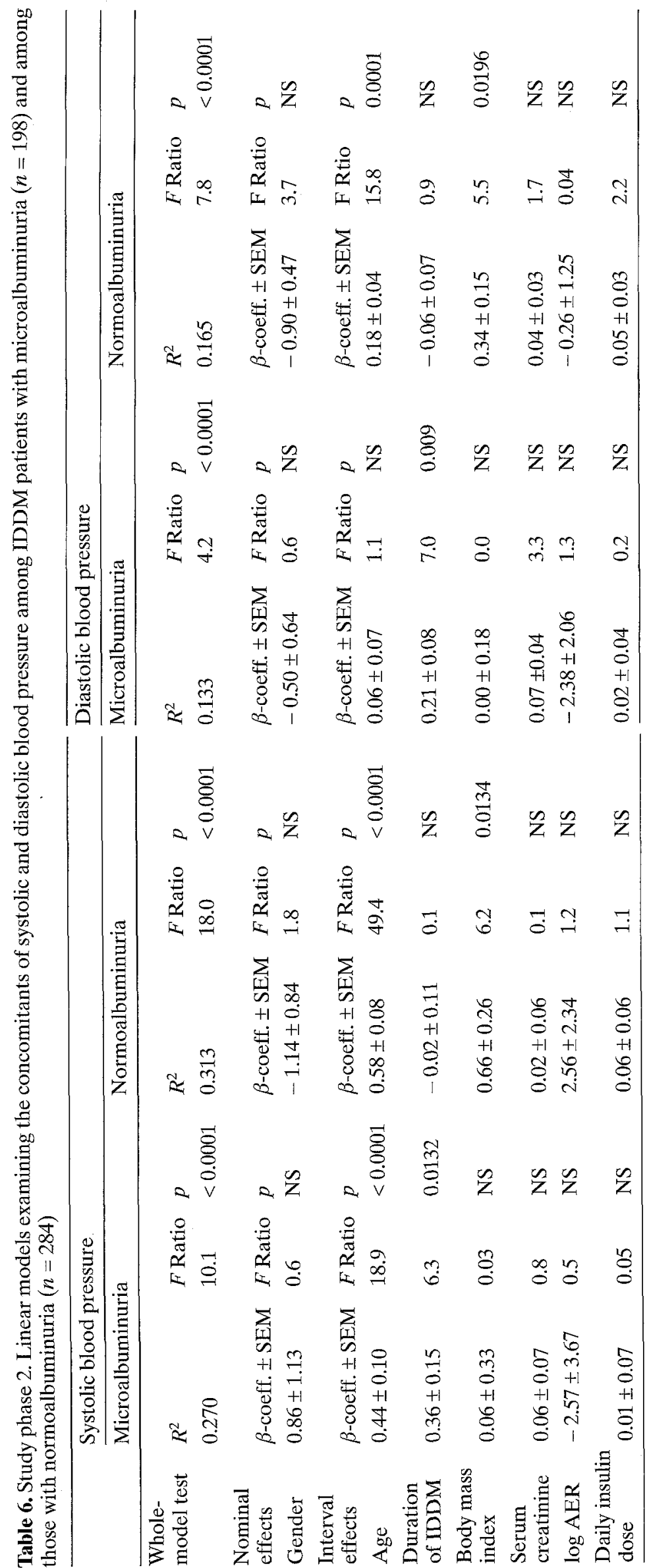


physical exercise [36], may parallel the above difference. $\mathrm{A} / \mathrm{C}$ is not an alternative to AER in the diagnosis of microalbuminuria, but our use of independent A/C levels which are known to detect AER above $20 \mu \mathrm{g} / \mathrm{min}$ with identical sensitivity and positive predictive value [28] may minimise the bias in the calculation of the expected rates. Our initial patients were not selected to represent all of those with a clinical record at participating clinics, as other studies have done [9-11]. It has been shown that if recruitment is made from patients attending the clinic twice per year, there is a lower chance of selecting patients with complications $[2,37]$. Under these assumptions, a $17.9 \%$ rate may be more representative, and comparable with a $14.9 \%$ estimate from Denmark [10], but remains less than the initial finding of a $27 \%$ prevalence also from Denmark [9]. A considerably lower rate of $3.7 \%$ was reported by the Microalbuminuria Collaborative Study Group [11], by re-examination of patients initially selected by less sensitive criteria, and with the restriction of the diagnosis of microalbuminuria to AER above $30 \mu \mathrm{g} / \mathrm{min}$.

Interestingly, about $11 \%$ of the patients with a short duration of diabetes may have microalbuminuric $\mathrm{A} / \mathrm{C}$ levels. This was not previously considered by two studies $[9,10]$ and could have been missed in a smaller sample of patients [11]. However, microalbuminuria is rare at IDDM onset [38], and our exclusion of patients with less than a 4-year duration may have positively biased our estimate.

Higher rates of microalbuminuria characterised patients later in the course of diabetes, and were not uncommon with long diabetes duration $[9,11]$, when the risk of developing nephropathy might be reduced $[1,2]$. The concomitants and outcome of microalbuminuria late in the course of diabetes are unclear [39-41]. Trends in the reduction of incidence of persistent proteinuria are generally assumed to parallel improvements in the standards of glycaemic control $[32,42]$, and may indicate a later development of microalbuminuria [26] or persistence of the subclinical stage [24-26]. Furthermore, poor glycaemic control is a known factor of progression to [43, 44] and through the course of microalbuminuria [41], and the trend to an inverse association of diabetes duration with glycated haemoglobin levels among our microalbuminuric patients may reflect this. Statistical modelling also suggested that blood pressures may be positively related to diabetes duration, independent of AER, only among the patients with microalbuminuria, suggesting that hypertension could be more common among those with a slow disease progression. This association was not detectable in the subset of patients who were normoalbuminuric at reexamination, where two common concomitants of hypertension, age and body mass index, were the predominant effects associated with blood pressure, and long diabetes duration could indicate protection from the risk of kidney damage $[1,2,13]$.

Interpretation of cross-sectional data should be conservative [45], and our study excludes from detailed evaluations the normoalbuminuric patients who initially screened negative. Furthermore, neither family history of hypertension nor erythrocyte sodium-lithium countertransport activity were considered. These may be positively associated with overt nephropathy [46-48], microalbuminuria [49, $50]$ and blood pressure $[14,50]$ in IDDM. In the single cohort study accounting for all these factors among patients with a 15-20 year diabetes duration, elevated sodium-lithium countertransport was related to higher risk of developing either nephropathy (in the presence of poor glycaemic control) or simple hypertension (with excellent glycaemic control). In contrast to the above observations, the risk of simple progression to microalbuminuria was predominantly attributed to poor glycaemic control, and not to elevated sodium-lithium countertransport, which did not reach significance [14].

While the nature of the genetic background of nephropathy is controversial $[48,51]$, our failure to associate microalbuminuria with poor glycaemic control may either parallel the above selection bias, or relate to the smaller power of cross-sectional evidence, where this relationship is likewise missed [9, $11,51,52]$. Also, the finding that a large majority of microalbuminuric patients may be candidates for the near-normalisation of glycaemia may be of little interest after the recent results of the Diabetes Control and Complications study [26]. This clearly indicated that intensive insulin treatment is highly relevant to the primary prevention of nephropathy, with microalbuminuria being delayed by several years [26]. Intensive insulin treatment can also delay the onset of diabetic retinal and neural abnormalities, thus encouraging early and aggressive correction of hyperglycaemia, irrespective of complications being present [26]. However, the incidence of microalbuminuria could not be entirely suppressed, and the target of near-normoglycaemia may not be feasible in all the patients randomised to intensive treatment [26]. Furthermore, the benefits of treatment must be weighted against the possibility of severe hypoglycaemia, supporting the prospective use of alternative measures in the prevention of nephropathy.

In line with several other studies, only a relatively small minority of our patients with microalbuminuria would be considered for treatment according to the conservative WHO diagnosis of hypertension [912]. Recent expansion of the criteria to include those with borderline hypertension may increase the number to $40-50 \%$, although a majority of these patients appear to be among those with long diabetes duration as expected [9]. Thus, current indications to treat hypertension in microalbuminuria are in favour 
of patients whose kidney damage follows a relatively benign course. In addition, the proportion of normoalbuminuric patients who may be considered for antihypertensive treatment following recent consensus has also considerably expanded, albeit less than in microalbuminuria. This intervention is justified in normoalbuminuria mainly because of cardiovascular considerations $[22,23]$, as its relevance to the primary prevention of nephropathy is not known, and findings that raised blood pressure may anticipate microalbuminuria remain controversial $[43,44,53]$.

A majority of the patients who present microalbuminuria early in the course of diabetes are normotensive if judged by the current criteria. While the presence of microalbuminuria per se may not always indicate a fast progression to proteinuria [41], two studies have now reported that the onset of proteinuria can be postponed by antihypertensive treatment in normotensive IDDM patients with microalbuminuria, independent of changes in glycaemic control [21,54]. Indeed, cost-benefit ratio analyses of screening for microalbuminuria, and administration of antihypertensive treatment irrespective of blood pressure in a computer-simulated cohort of these patients, have been consistent with life- and money-saving effects [55].

In conclusion, indications to treat borderline hypertension may largely implement the secondary prevention of nephropathy, although most patients are simply candidates for near-normalisation of glycaemia. Should the benefits of systemic blood pressure reduction among normotensive patients with microalbuminuria be confirmed, it might extend to microalbuminuria per se, and add to the benefits of nearnormalising glycaemic control.

Acknowledgements. We are indebted to Ms. P.Casalino and Ms. M. Pennacchioni for invaluable technical help. Part of this work was presented in preliminary form at the 14th Meeting of the International Diabetes Federation, Washington DC, June 23-28, 1991; and at the 27th Annual Meeting of the European Association for the Study of Diabetes, Dublin, September 11-14, 1991.

The Italian Microalbuminuria Study Group members were: Study Co-ordinator: G. Crepaldi.

Laboratories and co-ordinating clinics:

A. Bueti, F. Santeusanio, P. Brunetti; Chair of Medical Pathology, Policlinico Monteluce, University of Perugia. M. R. Cipollina, R. Nosadini, G. Crepaldi; Institute of Internal Medicine, Policlinico Universitario, University of Padua. R.Cortesi, I. Nosari, G. Pagani; Division of Endocrinology, Ospedali Riuniti, Bergamo. E.Daina, P.Ruggenenti, G.Remuzzi; Division of Nephrology, Ospedali Riuniti, Bergamo. P.Estivi, P. Cavallo-Perin, G.Pagano; Chair of Clinical Medicine, Institute of Internal Medicine, University of Turin. G. Galluzzo, A. Galluzzo, D. Bompiani; Chair of Clinical Medicine, University of Palermo. A. Giustina, G. Romanelli, G. Giustina; Chair of Clinical Medicine, Spedali Civili, University of Brescia. G. Penno, O. Giampietro, R. Navalesi; Chair of Clinical Medicine, Ospedale S.Chiara, University of Pisa. G.Petraroli,
F.Dani, Q.Carta; Diabetes Outpatient Clinic, Ospedale S. Giovanni Battista, Molinette, Turin. G.Piccini, S. Saffioti, G. Deferrari; Department of Internal Medicine, University of Genoa. P.Pietravalle, U.Di Mario, D. Andreani; Chair of Endocrinology and Metabolic Diseases, Policlinico Umberto I, University 'La Sapienza', Rome. G. Rigamonti, A. Canavesi, R.Spezia; Zeneca S.p.A., Basiglio, Milan. P.Tagliavini, R.Lugari, A. Gnudi; Chair of Clinical Medicine, Division of Endocrinology, Ospedale Maggiore, University of Parma. V.Trischitta, S. Squatrito, R. Vigneri; Division of Endocrinology, Ospedale Garibaldi, Catania. G. Zerbini, R.Mangili, G. Pozza; Chair of Clinical Medicine, Scientific Institute San Raffaele, University of Milan.

Participating Diabetes Outpatient Clinics by area

Bergamo: V.Bertone, Ospedale Bolognini, Seriate; L. Camerini, Ospedale Romano di Lombardia; B. Fardelli, Ospedale S.Biagio, Clusone; G.Lepore, Centro Antidiabetico, Ponte S.Pietro; A. Ongaro, Ospedale Pesenti Fenaroli, Alzano Lombardo; A.Spalluzzi, Ospedale S. Giovanni Bianco. G. Zibetti, Ospedale Briolini, Gazzaniga.

Catania: S. Leone, Ospedale Umberto I, Siracusa; L. Mughini, Ospedale Garibaldi, A. Tribulato, Ospedale Maggiore, Modica.

Genoa: L. Cataldi, Ospedale S. Martino; A.Pompei, Ospedale SS. Prospero e Caterina, Camogli; R. Prando, Dipartimento di Medicina Interna

Milan: G. Adda, Ospedale, S. Giuseppe, A. Bianchi, Ospedale di Passirana, Rho; G.P.Buratti, Ospedale Civile, Voghera; M. Cairo, Ospedale S. Famiglia, Erba; L. Capretti, Ospedale Civico, Codogno; F. Caviezel, Clinica Medica II, Università di Milano, S. Donato Milanese; I.Cazzalini, Ospedale Maggiore, Crema; A.Daprati, Ospedale Maggiore, Lodi; M.G.Fusi, ACISMOM; A. Gatti, Ospedale di Circolo, Varese; P. Gamba, Ospedale S.Gerardo Nuovo, Monza; R.Gandini, Ospedale V.Buzzi; P.Grandinetti, Centro Diabetologico, Seregno; G.Jan, Ospedale Bollate. G. Mariani, Ospedale S.Carlo; P. Mascetti, Ospedale S. Anna, Como; C.Mastaglio, H Moriggia-Pelascini, Gravedona; G.Morandi, Ospedal; S. Antonio Abate. Gallarate; F.Moratti, Ospedale Civili, Legnano; A. Nicodano, H Galmarini, Tradate. M.Poli, Ospedale S. Paolo; U.Raggi, Ospedale L. Sacco; A. Savastano, Ospedale di Circolo, Busto Arsizio; A. Scaldini, Ospedale S. Maria delle Stelle, Melzo; L. A. Scotti, H Uboldo, Cernusco sul Naviglio; G.Segalini, Ospedale Bassini, Cinisello Balsamo; G. Torchio, Ospedale G.Salvini, Garbagnate Milanese; A. Volta, Ospedale Sesto S. Giovanni

Padua: L. Chinello, Ospedale Civile, Dolo; L. Confortin, Ospedale Civile, Montebelluna; W.Donadon, Ospedale Pordenone; P.P.Faronato, Ospedale Civile, Feltre; F. Mollo, Ospedale Civile, Rovigo; A.Mongillo, Ospedale Civile, Belluno; M.Moretti, H Portogruaro. M.Morsiani, Ospedale S Anna, Ferrara; B. Muollo, Centro Antidiabetico, Este; C. Noacco, Ospedale Civile S. Maria della Misericordia, Udine; F. Riva, H Civile, Treviso; A. Tiengo, Istituto di Malattie del Ricambio, Policlinico Universitario, Padova; M. Velussi, Ospedale Civile, Monfalcone

Palermo: M. Russo, Ospedale Sciacca

Parma: P.G.Benedetti, Ospedale Policlinico, Modena; R. Biagioli, H Bufalini, Cesena; L. Boari, Ospedale Cremona; E. Bosi, Centro Antidiabetico, Guastalla; G. Fontana, Ospedale Civile, Sassuolo; D. Giorgi Pierfranceschi, Ospedale Civile, Piacenza; E.Maestri, Guastalla 2, Guastalla; G.Pietranera, Poliambulatorio Diabetologia, Reggio Emilia Perugia: C. Andreani, Servizio Diabetologico Conca Ternana, Terni; A. Angeli, Ospedale Civile, Gubbio; C. Campanelli, Ospedale Città di Castello; F. Capani, Clinica Medica, Università, Chieti; A.Coletti, Ospedale Civile, Gualdo Tadino; 


\section{R. Mangili et al.: Hypertension and microalbuminuria}

P. Compagnucci, Ospedale S.Maria della Pietà, Camerino; S. De Cosmo, Ospedale S. Giovanni Rotondo; G. Divizia, Ospedale Spoleto; P.Foglini, Ospedale Fermo; A. Figi, Ospedale Arezzo; P.Fumelli, INRCA, Ancona; C. Gatteschi, Ospedale Città della Pieve, Città di Pieve; E. Picchio, Policlinico Monteluce, Perugia; M.Pupillo, Ospedale Civile Renzetti, Lanciano; A. Travaglini, Centro Diabetologico, Terni; G. Vespasiani, Centro Antidiabetico, S Benedetto del Tronto; E. Vita Colonna, Ospedale SS Annunziata, Chieti

Pisa: M.A. Dolci, Ospedale SS. Giacomo e Cristoforo, Massa; C.Faloppa, Ospedale Civile Lotti, Pontedera; L.Fazzi, Ospedale Campo di Marte, Lucca; E.Ferrari, Ospedale Civile, Piombino; L.Fiaschi, Ospedale Civile, Volterra; R.M.Meniconi, Ospedale SS. Michele e Vincenzo, Camaiore; M.Rossi, Ospedale Misericordia, Grosseto; R.Trifirò, Ospedale Civile, Carrara

Rome: C.Caccamo, Ospedale Città di Aprilia, Aprilia; C. Teodonio, Ospedale S.Giovanni e dell'Addolorata; E.Del Toma, Ospedale Forlanini; G. Ghirlanda, Università Cattolica del Sacro Cuore, Istituto di Medicina Interna; P. L. Maestripieri, Ospedale S. Anna, Pomezia; G. Marozzi, Ospedale S. Spirito; G. Menzinger, Cattedra di Malattie Dismetaboliche, II Università; P. Montenero, F. Panza, SMOM Carturan Latina, Latina; A.Papa, Ospedale Rieti. L.Pisano, Ospedale S. Eugenio; S. Tamburrano, Ospedale Madonna delle Grazie, Velletri; D.Zappasodi, Ospedale Mazzoni, Ascoli Piceno Turin: E. Ansaldi, Ospedale Civile, Alessandria; G. Bargero, Ospedale S. Spirito, Casale Monferrato; M. Comoglio, Ospedale Civile, Carmagnola; S.Davì, Ospedale Civile, Susa; V.Ghia, Ospedale Civile, Asti; A.Marocco, Ospedale Civile, Rivoli; A. Rosatello, Ospedale Civile, Alba; R.Sivieri, Ospedale E.Agnelli; Pinerolo; F. Travaglino, Ospedale degli Infermi, Biella; M. Veglio, Ospedale Civile, Ivrea

\section{References}

1. Andersen AR, Christiansen JS, Andersen JK, Kreiner S, Deckert T (1983) Diabetic nephropathy in type 1 (insulindependent) diabetes: an epidemiological study. Diabetologia 25: 496-501

2. Krolewski AS, Warram JH, Christlieb AR, Busick EJ, Kahn CR (1985) The changing natural history of nephropathy in type I diabetes. Am J Med 78: 785-794

3. Borch-Johnsen K, Andersen PK, Deckert T (1985) The effect of proteinuria on relative mortality in type 1 (insulin-dependent) diabetes mellitus. Diabetologia 28: 290296

4. Borch-Johnsen K, Nissen H, Henriksen E et al. (1987) The natural history of insulin-dependent diabetes mellitus in Denmark: 1. Long-term survival with and without diabetic complications. Diabetic Med 4: 201-210

5. Christlieb AR, Warram JH, Krolewski AS et al. (1981) Hypertension: the major risk factor in juvenile-onset insulindependent diabetics. Diabetes 30 [Suppl 2]: 90-96

6. Parving $\mathrm{H}-\mathrm{H}$, Andersen AR, Smidt UM, Hommel E, Mathiesen ER, Svendsen PA (1987) Effect of antihypertensive treatment of kidney function in diabetic nephropathy. BMJ 294: 1443-1447

7. Parving H-H, Hommel E (1989) Prognosis in diabetic nephropathy. BMJ 299: 230-233

8. Lewis EJ, Hunsicker LG, Bain RP, Rohde RD, for the Collaborative Study Group (1993) The effect of angiotensinconverting-enzyme inhibition on diabetic nephropathy. $\mathrm{N}$ Engl J Med 329: 1456-1462

9. Parving H-H, Hommel E, Mathiesen ER et al. (1988) Prevalence of microalbuminuria, arterial hypertension, retinop- athy and neuropathy in patients with insulin-dependent diabetes. BMJ 296: 156-160

10. Nørgaard K, Feldt-Rasmussen B, Borch-Johnsen K, Sælan H, Deckert T (1990) Prevalence of hypertension in type 1 (insulin-dependent) diabetes mellitus. Diabetologia 33 : 407-410

11. Microalbuminuria Collaborative Study Group (1992) Microalbuminuria in type I diabetic patients: prevalence and clinical characteristics. Diabetes Care 15: 495-501

12. Gatling W, Mullee MA, Knight C, Hill RD (1988) Microalbuminuria in diabetes: relationships between urinary albumin excretion and diabetes-related variables. Diabetic Med 5: 348-351

13. Derby L, Warram JH, Laffel LMB, Krolewski AS (1989) Elevated blood pressure predicts the development of persistent proteinuria in the presence of poor glycemic control, in patients with type I diabetes. Diab Metab 15: 320 326

14. Barzilay J, Warram JH, Bak M, Laffel LMB, Canessa M, Krolewski AS (1992) Predisposition to hypertension: risk factor for nephropathy and hypertension in IDDM. Kidney Int 41: 723-730

15. Viberti GC, Hill RD, Jarrett RJ, Argyropoulos A, Mahmud U, Keen H (1982) Microalbuminuria as a predictor of clinical nephropathy in insulin-dependent diabetes mellitus. Lancet I: $1430-1432$

16. Parving H-H, Oxenbøll B, Svendsen PAa, Christiansen JS, Andersen AR (1982) Early detection of patients at risk of developing diabetic nephropathy. A longitudinal study of urinary albumin excretion. Acta Endocrinol 100: $550-555$

17. Mathiesen ER, Oxenbøll B, Johansen K, Svendsen PAa, Deckert T (1984) Incipient nephropathy in type 1 (insulindependent) diabetes. Diabetologia 26: 406-410

18. Mogensen CE, Christensen CK (1984) Predicting diabetic nephropathy in insulin-dependent patients. N Engl J Med 311: 89-93

19. Wiseman MJ, Viberti GC, Mackintosh D, Jarrett RJ, Keen H (1984) Glycaemia, arterial pressure and micro-albuminuria in type 1 (insulin-dependent) diabetes mellitus. Diabetologia 26: 401-405

20. Marre M, Chatellier G, Leblanc H, Guyene TT, Menard J, Passa P (1988) Prevention of diabetic nephropathy with enalapril in normotensive diabetics with microalbuminuria. BMJ 297: 1092-1095

21. Mathiesen ER, Hommel E, Giese J, Parving H-H (1991) Efficacy of captopril in postponing nephropathy in normotensive insulin dependent diabetic patients with microalbuminuria. BMJ 303: 81-87

22. The Working Group on Hypertension in Diabetes (1987) Statement on hypertension in diabetes mellitus. Final report. Arch Int Med 147: 830-842

23. Krans HMJ, Porta M, Keen H (1992) Diabetes care and research in Europe: the St Vincent Declaration action programme. Implementation document. Giorn It Diabetol 12 [Suppl 2]: 22-26

24. Feldt-Rasmussen B, Mathiesen ER, Jensen T, Lauritzen T, Deckert T (1991) Effect of improved metabolic control on loss of kidney function in type 1 (insulin-dependent) diabetic patients: an update of the Steno studies. Diabetologia 34: 164-170

25. Hasslacher Ch, Stech W, Ritz E (1985) Blood pressure and metabolic control as risk factors for nephropathy in type 1 (insulin-dependent) diabetes. Diabetologia 28: 6-11

26. The Diabetes Control and Complications Trial Research Group (1993) The effect of intensive treatment of diabetes on the development and progression of long-term compli- 
cations in insulin-dependent diabetes mellitus. $\mathrm{N}$ Engl $\mathbf{J}$ Med 329: 977-986

27. The Microalbuminuria Collaborative Study Group (1989) Sex, diabetes duration and microalbuminuria in IDDM. Diab Metab 14: 183

28. The Italian Microalbuminuria Study Group (1992) Prevalence of hypertension and microalbuminuria in adult type 1 (insulin-dependent) diabetic patients without renal failure in Italy. I. Validation of the screening techniques to detect microalbuminuria. Acta Diabetol 29: 156-166

29. Henry JB (1974) Clinical chemistry. In: Davidsohn I, Henry JB (eds) "Todd-Sanford" Clinical diagnosis by laboratory methods. 15th edn Saunders, Philadelphia, pp 594-596

30. Penno G, Clerico A, Cruschelli L et al. (1992) External quality control for radioimmunoassay of urinary albumin in diabetic subjects: a one-year experience. Clin Chem 38: 2333-2335 (Letter)

31. Borch-Johnsen K, Nissen H, Salling $N$ et al. (1987) The natural history of insulin-dependent diabetes in Denmark: 2. Long-term survival - who and why. Diabetic Med 4: $211-$ 216

32. Kofoed-Enevoldsen A, Borch-Johnsen K, Kreiner S, Nerup J, Deckert T (1987) Declining incidence of persistent proteinuria in type 1 (insulin-dependent) diabetic patients in Denmark. Diabetes 36: 205-209

33. Tarn AC, Thomas JM, Drury PL (1990) Correlates of blood pressure in young insulin-dependent diabetics and their families. J Hypertension 8: 795-803

34. Eshøj O, Feldt-Rasmussen B, Larsen ML, Mogensen EF (1987) Comparison of overnight, morning and 24-hour urine collections in the assessment of diabetic microalbuminuria. Diabetic Med 4: 531-533

35. Viberti GC, Bognetti E, Wiseman MJ, Dodds R, Gross JL, Keen $H$ (1987) Effect of protein-restricted diet on renal response to a meat meal in humans. Am J Physiol 253: F388F391

36. Viberti GC, Jarrett RJ, McCartney M, Keen H (1978) Increased glomerular permeability to albumin induced by exercise in diabetic subjects. Diabetologia 14: 293-300

37. Hammersley MS, Holland MR, Walford S, Thorn PA (1985) What happens to defaulters from a diabetic clinic? BMJ 291: 1330-1332

38. Lind B, Jensen T, Feldt-Rasmussen B, Deckert T (1989) Normal urinary albumin excretion in recently diagnosed type I diabetic patients. Diabetic Med 6: 682-684

39. Forsblom CM, Groop P-H, Ekstrand A, Groop LC (1992) Predictive value of microalbuminuria in patients with insulin-dependent diabetes of long duration. BMJ 305: 10511053

40. Marre M, Fressinaud P (1993) Predictive value of microalbuminuria in longstanding insulin dependent diabetes. BMJ 306: 271 (Letter)

41. Almdal T, Nørgaard K, Feldt-Rasmussen B, Deckert T (1994) The predictive value of microalbuminuria in IDDM: a five-year follow-up study. Diabetes Care 17: $120-125$
42. Bojestig M, Arnqvist HJ, Hermansson G, Karlberg BE, Ludvigsson J (1994) Declining incidence of nephropathy in insulin-dependent diabetes mellitus. N Engl J Med 330: 15-18

43. Microalbuminuria Collaborative Study Group United Kingdom (1993) Risk factors for development of microalbuminuria in insulin dependent diabetic patients: a cohort study. BMJ 306: 1235-1239

44. Coonrod BA, Ellis B, Becker DJ et al. (1993) Predictors of microalbuminuria in individuals with IDDM: Pittsburgh Epidemiology of Diabetes Complications Study. Diabetes Care 16: 1376-1383

45. Stephenson J (1991) Causal inference in diabetic nephropathy. Diabetologia 34: 62-63 (Letter)

46. Krolewski AS, Canessa M, Warram JH et al. (1988) Predisposition to hypertension and susceptibility to renal disease in insulin-dependent diabetes mellitus. N Engl J Med 318: $140-145$

47. Mangili R, Bending JJ, Scott G, Li LK, Gupta A, Viberti GC (1988) Increased sodium-lithium countertransport activity in red cells of patients with insulin-dependent diabetes and nephropathy. N Engl J Med 318: 146-150

48. Jensen J, Mathiesen E, Nørgaard K et al. (1990) Increased blood pressure and erythrocyte sodium-lithium countertransport activity are not inherited in diabetic nephropathy. Diabetologia 33: 619-624

49. Lopes de Faria JB, Friedman R, Tariq T, Viberti GC (1992) Prevalence of raised sodium-lithium countertransport activity in type 1 diabetic patients. Kidney Int 41: 877-882

50. Mangili R, Zerbini G, Barlassina C, Cusi D, Pozza G (1993) Sodium lithium countertransport and triglycerides in type 1 diabetes. Kidney Int 44: 127-133

51. Deckert T, Feldt-Rasmussen B, Borch-Johnsen K, Jensen T, Kofoed-Enevoldsen A (1989) Albuminuria reflects widespread vascular damage. The Steno hypothesis. Diabetologia 32: 219-226

52. Jerums G, Cooper ME, Seeman E, Murray RML, McNeil JJ (1987) Spectrum of proteinuria in type I and type II diabetes. Diabetes Care 10: 419-427

53. Mathiesen ER, Rønn B, Jensen T, Storm B, Deckert T (1990) Relationship between blood pressure and urinary albumin excretion in the development of microalbuminuria. Diabetes 39: 245-250

54. Viberti GC, Mogensen CE, Groop LC, Pauls JF, for the European Microalbuminuria Captopril Study Group (1994) Effect of captopril on the progression to clinical proteinuria in patients with insulin-dependent diabetes mellitus and microalbuminuria. JAMA 271: 275-279

55. Borch-Johnsen K, Wenzel H, Viberti GC, Mogensen CE (1993) Is screening and intervention for microalbuminuria worthwhile in patients with insulin dependent diabetes? BMJ 306: 1722-1725 